\title{
SOBRE UMA COSMOLOGIA BERGSONIANA
}

\section{GEOVANA DA PAZ MONTEIRO ${ }^{1}$}

RESUMO: Tendo em vista que a ciência contemporânea constitui o horizonte no qual se situa o pensamento de Henri Bergson desde sua origem, buscaremos neste artigo discutir a passagem da obra de 1907, A evolução criadora, na qual o filósofo elabora algumas ideias para certa cosmologia amparada na compreensão da duração como tecido próprio do real. A descrição dessa cosmologia aparece-nos como o corolário de sua proposta de uma nova metafísica, agora dinâmica, cravada na experiência, ou seja, na temporalidade.

Palavras-chave: Duração; Cosmologia; Henri Bergson.

ABSTRACT: Since contemporary science is the horizon on which Henri Bergson's thought is situated since its origin, we will seek in this article to discuss the passage from the book of 1907, The creative evolution, in which the philosopher elaborates some ideas for a certain cosmology supported by the understanding of duration as the actual foundation of the real. The description of this cosmology appears to us as the corollary of its proposal of a new metaphysics, now dynamic, embedded in experience, that is, in temporality.

KEYWORDS: Duration; Cosmology; Henri Bergson.

\section{Considerações iniciais}

A pergunta sobre a gênese do universo paira desde sempre no imaginário humano. As diversas respostas que tal questão suscita são provenientes, sobretudo, das religiões, da filosofia e da ciência. Não obstante sua variedade, as explicações míticas sobre a origem do mundo parecem compor-se frequentemente de determinados modelos os quais se repetem em alguma medida de cultura para cultura. E, ao contrário do que se poderia supor, alguns elementos dessas cosmogonias convertem-se em teorias cosmológicas filosóficas e científicas as mais sofisticadas.

Entre os mitos de criação ocidentais, por exemplo, podemos notar a recorrência de certos padrões simbólicos na representação do surgimento da matéria e da vida. Observamos tanto na mitologia grega quanto na judaica (bíblica) a ideia do universo organizado a partir de dualidades bem demarcadas, as quais teriam sua origem de uma confusão inicial, um caos

\footnotetext{
${ }^{1}$ Professora Adjunta de Filosofia da Universidade Federal do Recôncavo da Bahia (UFRB). Doutora em Filosofia pela Universidade Federal da Bahia (UFBA). E-mail: geovanamonteiro@yahoo.com.br.
} 
primordial cuja ordenação seria dada por um ser ou seres alheios à desordem e à temporalidade. A dualidade fundamental em tais mitos é, portanto, a da ordem-desordem.

Um lance de olhos para os mitos gregos nos revelará a origem do cosmos contada como obtendo seu início de Abismo ou Caos (Kháos). Caos “é um vazio [...] escuro onde não se distingue nada. Espaço de queda, vertigem e confusão, sem fim, sem fundo" (VERNANT, 2015, p. 17). Esse Abismo confuso reaparece de maneira semelhante no livro de Gênesis (1: 1-5) quando descreve: "No princípio, Deus criou o céu e a terra. E a terra era informe e vazia. E havia trevas sobre a face do abismo". A partir das trevas do abismo o artifício divino imporá ordem ao caos (desordem), separando elementos como dia e noite, terra e céu. Se continuarmos comparando a mítica bíblica com a grega, observaremos que é também de Caos que aparece Gaia (Terra): “À confusão e à tenebrosa indistinção de Caos opõe-se a nitidez, a firmeza e a estabilidade de Gaia" (VERNANT, 2015, p. 17).

Percebemos então o fato de que, tanto no mito grego quanto no judaico, o tempo começa com a ordem a partir do caos. Então responder à pergunta sobre a singularidade inicial equivalerá a uma resposta à origem do tempo. Mas o tempo, nas culturas ocidentais, será explicado, via de regra, por causas atemporais. Na passagem da visão de mundo mítica (cosmogônica) para a filosófica, com efeito, os antigos gregos costumavam determinar fundamentos atemporais para a origem do todo, o que deu margem a uma cosmologia fechada, apoiada na ideia de um universo completo que encontraria seu fundamento último no eterno. No que concerne, por sua vez, à tradição judaico-cristã, a criação do universo seria produto de um deus transcendente que criou tudo o que existe a partir do vazio informe. Esta concepção encontrará respaldo na tradição grega, sobretudo em Platão e Aristóteles. Eis aí, em resumo, a admissão de uma causa criadora transcendente, eterna e imutável, a qual, ao criar o mundo, cria também o tempo, não obstante ela própria seja atemporal.

Os modernos, embora tenham admitido uma cosmologia mais aberta em relação à dos antigos e medievais, ainda estariam presos à concepção estática do cosmos quando eliminam de sua compreensão qualquer sombra de tempo qualitativo. $\mathrm{O}$ universo moderno é totalmente relativo à ordem geométrica, e ainda que se admitisse não se conhecer o todo, seria possível, por meio do cálculo e da medida, prever com segurança matemática a totalidade dos eventos futuros. Afinal, se o cosmos é geometricamente ordenado, não haverá evento físico passado, presente ou futuro que não se possa determinar (KOYRÉ, 2006). 
Analisando então esse percurso das idéias cosmogônicas e cosmológicas da tradição ocidental, Henri Bergson observou que a causa da criação sugerida por antigos, medievais e modernos, “[...] não poderia instalar-se no tempo concreto, no tempo que sentimos ser o tecido mesmo de nossa vida". Sendo assim, resultaria de tal concepção a aceitação de que “[...] tudo está dado de uma vez por todas" (BERGSON, 2005, p. 261). Uma vez realizada a passagem das "trevas à luz", tudo teria sido criado, instantaneamente, do vazio informe, e por uma causa ou causas atemporais.

Bergson pretenderá doravante recuperar o papel do tempo na criação, é disso enfim que trata sua evolução criadora. Através da imagem do Elã vital, o filósofo adentrará os temas da evolução e da cosmologia. A imagem do elã será recorrente na obra de 1907 e ilustrará sempre, em sentido mais genérico, a ideia da vida como um ato único, que se individualiza por um processo múltiplo e fundante, a saber, a duração. O elã é um impulso inicial de criação (BERGSON, 2005, p. 59) cuja representação, portanto, contribuirá para uma conciliação entre as noções de imprevisibilidade e finalidade que essa filosofia da natureza reivindica. Por esta via, pretende-se então vencer o mecanicismo estabelecendo não um princípio inteligente, um desígnio criador para o qual a ordem do todo aspira, mas a participação do todo em uma causa comum (WORMS, 2011, p. 222).

Mas, de partida, poderíamos indagar: em que medida a explicação bergsoniana também não encontraria seu molde numa visão mítica de mundo? Afinal, para além das cosmogonias ocidentais aqui destacadas, é possível recorrer, por exemplo, à tradição hindu, na qual a produção do cosmos não se dá sem a influência temporal. No hinduísmo não se crê que o universo tenha sido criado instantaneamente, pois o todo é eterno e cíclico (eterno retorno). ${ }^{2}$ Assim, a dualidade ordem-desordem se manifesta representada pela dança de criação e destruição do deus Xiva (GLEISER, 2013, p. 24). Decorre dessa cosmogonia hindu uma compreensão criativa-destrutiva do cosmos que, aparentemente, poderia encontrar eco nas ideias de Bergson. Mas há detalhes para os quais precisamos atentar a fim de iniciarmos a discussão das ideias cosmológicas deste filósofo.

Defendendo a tese segundo a qual seria necessário compreender a gênese da matéria não de um só golpe, mas como uma criação contínua, encontramos a seguinte afirmação de Bergson (2005, p. 261-262):

\footnotetext{
${ }^{2} \mathrm{O}$ etoicismo grego também elaborou uma concepção cósmica amparada na noção de "eterno retorno", a qual mais tarde será recuperada por Nietzsche, mas esta visão de mundo não prevaleceu no ocidente, tendo sido escamoteada pela assimilação das doutrinas platônica e aristotélica pelos medievais.
} 
[...] o mistério que paira sobre a existência do universo provém, em grande parte, de querermos que sua gênese se dê de um só golpe, ou então que toda matéria seja eterna. [...] Uma vez erradicado esse prejuízo, a ideia de criação torna-se mais clara, pois se confunde com a de crescimento.

Esta passagem nos aparece como uma recusa à ideia de criação instantânea, mas também a recusa à tese da eternidade do universo apresentada na mítica hindu. O filósofo está interessado, sobretudo, em desfazer-se de moldes metafísicos estáticos, daí sua impossibilidade de aceitar a eternidade do universo, ainda que esta implicasse um movimento cíclico de "eterno retorno". Além disso, Bergson (2005, p. 262) também nos adverte para o fato de que as leis de nosso mundo talvez não se apliquem a outros, admitindo a possibilidade de múltiplos universos (multiverso), alguma coisa que somente será discutida no horizonte da física contemporânea, levando-se em conta as teses tanto da relatividade geral quanto da mecânica quântica, as quais o próprio filósofo não aprofundou em sua obra.

Será, pois, a favor da transposição de qualquer determinismo aplicado à criação que Bergson defenderá a evolução criadora. Para tanto, será necessário reconsiderar, agora sob a ótica da experiência temporal, as noções de ordem e desordem, o que fará apoiado, sobretudo, nas leis da termodinâmica. Pretendemos averiguar daqui em diante até que ponto suas explicações ou teses cosmológicas soam coerentes e em que medida elas podem se relacionar com os rumos da física contemporânea.

\section{Ordem e desordem}

Contrapondo-se à tendência clássica de geometrização do universo, Bergson (2005,p. 236-237) dirá: “[...] nenhuma complicação da ordem matemática consigo mesma, por engenhosa que se a suponha, introduzirá um átomo de novidade no mundo”. A novidade só pode provir, segundo ele, da própria duração em sua potência criativa. Em uma palavra, a novidade provém da evolução criadora. A ordem matemático-geométrica representa, por fim, a interrupção do impulso criador, ela exterioriza enfim uma tendência negativa do elã vital, negativa porque não cria, apenas repete.

As leis do mundo físico exprimiriam essa negatividade, uma vez que nenhuma delas individualmente possui realidade objetiva, por seu caráter conceitual, genérico, ao ponto de não se referirem a nada de concreto no mundo material. Tais leis seriam completamente aplicáveis à matéria se esta fosse absolutamente idêntica ao espaço. Mas como a matéria será 
compreendida também como um ritmo de duração, ela não equivalerá em absoluto ao espaço puro, embora haja entre ambos uma aproximação tal que permitirá o estabelecimento da ciência (BERGSON, 2005, p. 237).

Não será nunca demasiado insistir, portanto, na insuficiência da mensuração, na artificialidade das leis físicas quando aplicadas à natureza e, com isto, à duração (MONTEIRO, 2012). A natureza, entregue a seu próprio fluxo, não mede nem conta, medir é próprio do homem, “[...] implica sobrepor real ou idealmente dois objetos um sobre o outro um certo número de vezes"(BERGSON, 2005, p. 238). E neste trabalho de mensuração e de cálculo a ciência é bem sucedida porque eleva ao limite, isto é, ao espaço homogêneo, o prolongamento do movimento ou tendência à materialidade identificado à própria inteligência. A natureza, no entanto, não corresponderia em absoluto às leis que a ela se aplicam. Assim, nossa ciência, na visão bergsoniana, deverá ser compreendida em sua contingência, relativa à ordem e às variáveis com as quais ela própria escolheu lidar (BERGSON, 2005, p. 239).

Mediante a constatação de que a inteligência e a matéria são naturalmente aproximadas por sua gênese, supõe-se equivocadamente, segundo Bergson, uma ordem inteligente no universo. A partir desta ordem seria possível determinar padrões e leis infalíveis, válidas desde sempre. Em suma, aos olhos do filósofo, a ideia de uma ordem geométrica sobrepondo-se à total desordem material subjaz à própria racionalidade. Como bem esclareceu Worms (2011, p. 255, grifos do autor): "Longe de poder conceber-se como a parte e o efeito de algo que a supera, nossa inteligência se concebe, pois, como o que acrescenta unidade a um real confuso e desordenado que a precede". A ciência veria algo de extremamente positivo nessa vitória da geometria sobre o caos.

Mas a que desordem o pensamento científico-especulativo se refere quando a pressupõe sobre o mundo material? Para Bergson (2005, p. 240-241) considerar que um sistema esteja desordenado equivale a tomar uma ordem qualquer encontrada por inferior à ordem buscada. Desta maneira, a ideia de desordem implicaria, em última instância, o estabelecimento de uma forma previamente dada à matéria tida como informe ou desordenada. No limite, equivaleria à suposição de um substrato absoluto para a realidade, implicando diretamente a negação da própria matéria em sua diversidade. 
Em suma, pela palavra "desordem" representamos nossa frustração com uma ordem atualmente desnecessária (BERGSON, 2005, p. 242). A palavra não possuiria, portanto, uma aplicação teórica, mas prática, sendo um artifício da linguagem para denotar ausência, embora a ausência seja sempre percebida pela presença de outra ordem qualquer. A desordem seria, pois, uma ordem não esperada uma vez que, "de um modo geral, a realidade é ordenada na exata medida em que satisfaz nosso pensamento" (BERGSON, 2005, p. 242, grifo do autor). Eis aía tendência intelectual do elã vital. Por outro lado, em sua tendência estritamente espiritual, encontraríamos outro tipo de ordem, a da criação de novidade.

Nos dois casos há ordem, porém, distintas. No primeiro caso, comanda a relação de causa e efeito determinada como necessária. No segundo, embora fosse possível associar a ordem vital a certa concepção finalista, ela extrapola em muito esta doutrina, uma vez que seja admitida a imprevisibilidade das formas criadas (BERGSON, 2005, p. 243). Uma importante característica distintiva entre a ordem geométrica e a ordem vital é o fato de que na primeira impera a necessidade e o automatismo, ao passo que na segunda algo de voluntário e, portanto, livre. Cabe-nos agora perguntar: com base em quais leis o universo de Bergson poderá ser regido, haja vista o fato deste mundo indeterminado estar em constante mudança?

\section{As leis da termodinâmica e a interpretação de Bergson}

$\mathrm{Na}$ cosmologia bergsoniana, “[...] o universo não está feito, mas faz-se incessantemente" (BERGSON, 2005, p. 262). Esta visão está de acordo com algumas concepções da Termodinâmica, ciência que constitui um dos três pilares da física clássica (juntamente com a mecânica newtoniana e o eletromagnetismo), cuja área de domínio são as mudanças ocorridas em um sistema físico do ponto de vista da troca de calor. A termodinâmica deriva em leis empiricamente corroboradas, das quais duas serão discutidas por Bergson n'A evolução criadora. ${ }^{3}$

A primeira lei afirma que a energia do universo é constante, donde deriva o princípio da conservação da energia, cuja aplicação hoje não se restringe a fenômenos físicos, mas abrange os químicos e biológicos. Em resumo, a primeira lei determina a possibilidade de

\footnotetext{
${ }^{3}$ Bergson já havia discutido este tema no terceiro capítulo de seu primeiro livro, o Ensaio sobre os dados imediatos da consciência (p. 99-110). Mas ali o filósofo não chega a abordar a segunda lei, esta será apenas interpretada n'A evolução criadora, obra a partir da qual limitaremos nossa discussão neste artigo.
} 
alteração do estado termodinâmico do sistema através da troca de calor ou da realização de trabalho. Já a segunda lei, conhecida como a lei da irreversibilidade dos processos naturais, diz que a entropia do universo tende a um máximo. Ou seja, considerando a irreversibilidade dos processos naturais, a energia não utilizada em um trabalho se degrada, o que, por sua vez, implicará o conceito de entropia. Entropia é a grandeza termodinâmica que mede o grau de irreversibilidade de um sistema, isto é, o seu grau de "desordem".

Conforme a segunda lei, não é possível converter completamente a energia térmica em trabalho, de modo que o grau de entropia de um sistema corresponderá à quantidade de energia inutilizada, aquela que não mais se transformará em trabalho. Em suma, se a entropia mede o grau de degradação de um sistema, quanto mais desordenado, maior a entropia. Por isto, a segunda lei da termodinâmica é atualmente mais conhecida como "princípio de aumento da entropia." Assim, se a primeira corresponde à conservação, a segunda corresponde a um processo de evolução, que significa aqui desperdício de energia. Este princípio é constatado em todos os processos naturais e irreversíveis, pois nestes a entropia tende a um máximo. Entretanto, em um sistema idealizado em que há um processo isotérmico seria possível constatar a invariância da entropia. Ou seja, em estados de equilíbrio térmico a entropia seria nula.

Mediante essas breves considerações acerca das duas primeiras leis da termodinâmica, estamos em condições agora de observar a interpretação positiva que Bergson dará à segunda, ou seja, veremos como ela se adequaria à concepção da duração como tecido próprio de todo o universo. De partida, o filósofo atribuirá à segunda lei um alcance metafísico mais amplo, uma vez que a primeira é, segundo ele, meramente quantitativa, relativa a determinados padrões de medida. Segundo sua formulação, esta lei apenas "estabelece que, num sistema que se supõe fechado, a energia total, isto é, a soma das energias cinética e potencial, permanece constante" (BERGSON, 2005, p. 263). Ou seja, desde sua origem a quantidade de energia cósmica seria a mesma. Tratar-se-ia então de uma lei artificial, haja vista o fato de haver no universo outros tipos de energia além da cinética, bem como diversos tipos de energia potencial que diferem qualitativamente antes que quantitativamente. Portanto, a primeira lei deveria ser vista com cautela quando se pretende estabelecer os princípios que regem o todo, pois uma lei quantitativa poderá no máximo informar “[...] antes sobre a relação de um fragmento desse mundo com um outro fragmento do que sobre a natureza do todo" (BERGSON, 2005, p. 263). 
Considerando agora a segunda lei da termodinâmica, supostamente a mais metafísica de todas as leis da física, princípio que estabelece a degradação da energia, Bergson (2005, p. 264) dirá que esta não versa sobre grandezas, daí em parte o seu caráter metafísico. Tratar-seia de uma lei bastante intuitiva, pois, prescindindo da interpretação simbólica ou dos padrões de medida, seria perfeitamente análoga à experiência da "[...] direção na qual caminha o mundo" (BERGSON, 2005, p. 264), ou seja, a tendência universal à irreversibilidade do tempo. Para Bergson, essa irreversibilidade expressa implicitamente na lei da entropia não constitui apenas uma característica presente em processos termodinâmicos, mas também nos psicológicos, bioquímicos e físicos em geral. A segunda lei expressaria, portanto, a irreversibilidade do contínuo fluxo da duração em geral.

Mas, considerando a irreversibilidade dos processos termodinâmicos, uma ameaça ronda a manutenção da vida e da evolução. Vejamos: o sistema solar esgota a cada instante um pouco de sua mutabilidade, isto é, de sua transformação. Porém, se esgota seu potencial de transformação, poder-se-ia supor um limite implícito à concepção deste esgotamento paulatino, um estado de equilíbrio termodinâmico onde a vida não fosse mais possível. Dada essa possibilidade, seria permitido supor o início do universo organizado, mas também o seu fim.

A consequência final da termodinâmica seria então a "morte térmica" do universo. Esse problema foi enfrentado no século XIX (1872) pelo físico austríaco, Ludwig Boltzmann, ${ }^{4}$ embora sua teoria não tenha sido bem aceita pela comunidade científica da época (PRIGOGINE, 2002, p. 17). A partir das ideias de Boltzmann, se a instabilidade provém de um estado geral de estabilidade, e se no momento atual do universo se constata a degradação da energia utilizável, haveria então a possibilidade de uma regressão cíclica deste estado, um retorno ao estado inicial bem como sua sucessiva degradação. ${ }^{5}$ Essa possibilidade então entraria em acordo com o modelo determinístico clássico, cujos termos seguem o pressuposto deque todos os processos mecânicos do universo são reversíveis.

Reinterpretando Boltzmann a seu modo, Bergson (2005, p. 265-266) afirma, forçosamente, que a teoria da morte térmica do universo é “[...] de uma improbabilidade matemática que ultrapassa toda imaginação e que equivale, praticamente, à impossibilidade

\footnotetext{
${ }^{4}$ Ludwig Boltzmann (1844-1906), físico e filósofo da ciência austríaco que introduziu um importante elemento à teoria do crescimento da entropia em sistemas termodinâmicos desordenados, a saber, o coeficiente probabilístico.

${ }^{5} \mathrm{O}$ modelo mítico hinduísta encontraria aqui seu correspondente científico.
} 
absoluta”. Conforme destacou M. Capek (1971, 372-373), Bergson chama imprecisamente a seu favor as teses de Boltzmann, cuja visão cosmológica implica o modelo cinéticocorpuscular clássico, ou seja, o físico buscava, ao contrário do filósofo, resolver o "paradoxo do tempo" salvando a reversibilidade. Bergson preferiu, no entanto, identificar "extrema improbabilidade" com "impossibilidade". De fato, Boltzmann fala, segundo Capek, de uma possibilidade mínima da reversão da entropia do universo a zero, mas jamais de uma impossibilidade. E, em suma, o físico rejeita a ideia de um único tempo cósmico, o que, sabemos, é contrária às ideias bergsonianas.

De todo modo, Bergson (2005, p. 266) acredita que o problema cosmológico seja insolúvel em termos físicos e, portanto, buscará uma solução "extra-espacial", nos termos metafísicos de sua fillosofia, inversa ao modelo determinístico da física moderna. Mas o que significaria finalmente uma solução "extra-espacial"? ${ }^{6}$ Tratar-se-ia aqui de dar respostas a um problema físico a partir de uma solução metafísica? Caberia, para o filósofo, realmente à filosofia adentrar o terreno em que a ciência encontra seu limite. Mas, poderíamos perguntar: não seria este também o limite da metafísica? Não, para Bergson.

$\mathrm{Na}$ concepção bergsoniana, as ideias físicas estão lastreadas de espacialidade, haja vista suporem “[...] uma coincidência perfeita da matéria com o espaço abstrato" (BERGSON, 2005, p. 265). É neste sentido então que a lei da entropia concretizaria em termos físicos a tendência metafísica da matéria à espacialização, ou seja, à sua degradação. Logo, considerando-se a segunda lei, o crescimento da entropia corresponderia a um processo estéril, não criativo que, no limite, levaria à possibilidade da destruição de tudo. Bergson, ao contrário da maioria dos físicos, verá nesse crescimento algo de positivo.

Conforme as ideias apresentadas n'A evolução criadora, a ordem traduzida pelas leis da natureza nasceria de uma inversão do fluxo do elã vital. Mas a segunda lei da termodinâmica indica em tal inversão um processo de degradação, ou seja, "[...] a ideia de uma coisa que se desfaz" (BERGSON, 2005, p. 266, grifos do autor). Com efeito, este seria o traço fundamental da matéria. Por outro lado, se a matéria caminha para sua degradação, o espírito, ao contrário, caminha para sua criação, é "coisa que se faz" diversamente aos processos físicos, uma vez que seja imaterial.

\footnotetext{
${ }^{6}$ Segundo Capek, Jacques Chevalier, discípulo de Bergson, e seu oponente René Berthelot interpretaram essa causa "extra-espacial" de Bergson como a defesa da tese teológica do criacionismo instantâneo. Mas essa interpretação é equivocada, pois a ideia de criação em Bergson implica a de continuidade, algo que será vinculado à interpretação da lei da entropia. (CAPEK, 1971, p. 373).
} 
Mas, conforme as teses d'A evolução criadora, a vida que evolui se vincula diretamente à matéria, ela não é espiritualidade pura. Se assim fosse, não haveria degradação, apenas pura criação. A vida, dirá Bergson (2005, p. 267), “na verdade, está cravada em um organismo que a submete às leis gerais da matéria inerte. Mas tudo se passa como se fizesse todo o possível para libertar-se dessas leis". Ora, a evolução vital se dá basicamente impulsionada pela energia, isto é, todos os processos vitais, sejam os que se sucedem no animal ou no vegetal, fazem uso dela, conservando-a ou consumindo-a. Porém, o fluxo vital, ainda assim, não é capaz de "[...] deter a marcha das mudanças materiais" (BERGSON, 2005, p. 267, grifo do autor), ou seja, o vivo não é capaz de reverter o processo material em vista de sua degradação; em suma, não há como fugir à finitude. Assim sendo, a duração dos organismos vivos consistiria em uma luta constante da vida contra a morte, um esforço que apenas retarda o processo, mas não seria capaz de evitá-lo.

Contudo, como dissemos acima, Bergson não concluirá negativamente essa marcha para a morte, seja na vida orgânica seja na matéria inorgânica. Poder-se-ia interpretar a morte dos vivos, bem como a degradação da matéria em calor, positivamente uma vez que se considerem tais processos como criativos e não destrutivos. Admitir-se-á então que

\footnotetext{
ao lado dos mundos que morrem, sem dúvida há os que nascem. Por outro lado, no mundo organizado, a morte dos indivíduos não aparece de modo algum como uma diminuição da 'vida em geral', ou como uma necessidade à qual esta se submeteria a contragosto. (BERGSON, 2005, p. 268, nota de rodapé número 13).
}

Notamos então que o filósofo concorda em ver na degradação da energia a parte de um processo cíclico do universo, contribuindo para "o maior progresso da vida em geral" (BERGSON, 2005, p. 268). Mas não seria um ciclo qualitativamente repetitivo, ou seja, o ciclo da vida deve ser contínuo, porém, variado, conforme a duração de seu fluir. Como vimos, essa ideia de uma regeneração contínua do todo já está presente em cosmogonias antigas, bem como na física contemporânea. Porém, segundo observou Capek (1971, p. 368395), Bergson não parece defender com isto a eternidade do universo, ou mesmo sua infinitude, coisa que, diga-se de passagem, seria totalmente contrária à sua crítica à tradição.

Se retomarmos agora a consideração da solução metafísica de Bergson para o problema da criação, é preciso notar que quando o filósofo se refere à origem do universo a partir de uma "causa" extra-espacial não trata ali de um único ato criador, mas de um processo (CAPEK, 1971, p. 374). O termo "processo" sugere então uma ação contínua, não um ato completamente determinado, instantâneo. Portanto, se não temos aqui uma cosmologia 
criacionista no sentido clássico, nem uma que considere a eternidade do cosmos, a posição de Bergson parece caminhar para uma visão cosmológica finitista. Isto é, uma que considera a finitude do passado cósmico e de seu crescimento qualitativo como duração. Tais ideias se aproximam bastante das teses de G. Lemaître, astrônomo e físico belga que associou o afastamento das galáxias à segunda lei da termodinâmica, reinterpretando-a segundo a teoria quântica.

Para Lemaître, a história do universo começa de uma superexplosão radioativa, o chamado big bang, a partir de um único átomo (singularidade). ${ }^{7}$ Doravante, o desenvolvimento ordenado do todo tem se dado a partir dos fragmentos daquele "ovo cósmico". Portanto, a degradação da energia constatada na lei da entropia deveria ser interpretada como uma fragmentação contínua, não mais em termos destrutivos. Sendo assim, tempo e espaço teriam seu surgimento derivado desse mesmo processo, ou seja, se encontrariam em via de crescimento desde então. Tempo e espaço assim entendidos não se separam mais de seu conteúdo físico, contrariando a interpretação clássica.

De acordo com Capek (1971, p. 381), entendido a partir do modelo einsteiniano, o espaço será incorporado por Lemaître no processo de desenvolvimento do universo, ou seja, o espaço agora se expande, não sendo mais pensado como uma estrutura rígida e imutável, porque gerado a partir do primeiro evento cósmico, assim como o tempo. Isto se aproxima das ideias de Bergson na medida em que, para este, o espaço, sendo um limite ideal, também foi derivado da natureza em seu fluir pela via da materialidade. Mas, assim como se encontram semelhanças nestas visões, encontram-se também divergências. Bergson sempre se referiu ao espaço euclidiano, ao contrário de Lemaître que, inserido no contexto da relatividade geral negligenciado por Bergson, admite outra concepção, o espaço encurvado pela gravidade. Portanto, pode-se também concluir que a semelhança nas duas visões cosmológicas seja, até certo ponto, uma coincidência. Porém, não uma mera coincidência, já que, de fato, ambos incorporam o espaço no processo cosmológico. Em primeiro lugar porque acreditam no começo do tempo e, em segundo, porque não pensam uma cosmologia criacionista teísta em sentido tradicional. Enfim, tanto para um quanto para o outro, a criação não é nem instantânea nem provém de uma causa transcendente, ela obedece um processo gradual. Ambos levam em conta o aspecto dinâmico da realidade física.

\footnotetext{
7 “The original single quantum”. (CAPEK, 1971, p. 378)
} 
Mas, para além da semelhança com a cosmologia de Lemaître, as ideias de Bergson também se aproximariam da interpretação que outros físicos deram à segunda lei da termodinâmica. Como vimos, Bergson relacionou o crescimento da entropia a uma tendência natural da matéria à homogeneidade, ou seja, à espacialização. De acordo com Capek, em outros termos, essa interpretação fora também sustentada por Mach, Duhem e por outros energeticistas. Entretanto, conforme o comentador, o filósofo não soube perceber que a teoria cinética do calor, em alguns aspectos, no futuro entraria em acordo com sua filosofia, desde que o modelo determinístico do universo fosse substituído pelo modelo atômico da mecânica quântica (CAPEK, 1971, p. 381-382).

Eis, então, o próprio fluxo da duração, evidenciado finalmente tanto na matéria inerte quanto nos organismos vivos. Assim, Bergson (2005, p. 269) completará seu argumento afirmando que "a criação de um mundo é um ato livre e a vida, no interior do mundo material, participa dessa liberdade". Não apenas a vida participaria deste ato, mas também a matéria, embora em grau muito menor, dada sua tendência natural à espacialização. A matéria será entendida como a marca de um ato ou gesto criador evanescente, como uma parte da realidade que se desfaz. A vida, por sua vez, seria a subsistência, na matéria, da energia que aos poucos se dissipa; enfim, "uma realidade que se faz através daquela que se desfaz" (BERGSON, 2005, p. 269, grifos do autor).

\section{Sobre Bergson e Prigogine}

Além das possíveis associações entre as ideias metafísicas de Bergson e as interpretações de físicos contemporâneos a ele para a segunda lei da termodinâmica, e além da associação específica com a teoria de Lemaître, poderíamos pensar agora a reconsideração de suas ideias a partir do olhar de Ilya Prigogine ${ }^{8}$ (1917-2003), físico-químico russo, naturalizado belga, que atribui grande valor ao pensamento bergsoniano acerca da duração como um fluxo contínuo e irreversível. Assim como Bergson, Prigogine sugere uma "nova aliança" entre o homem e a natureza, considerando que o antigo modelo determinístico começa a ceder espaço a outras concepções as quais levam em conta agora a "flecha do tempo" como capaz de criar uma ordem universal dinâmica.

\footnotetext{
${ }^{8}$ Prigogine se tornou célebre por ter recebido, em 1977, o Prêmio Nobel de Química, por seus estudos na área da irreversibilidade e da termodinâmica dos sistemas complexos.
} 
Segundo afirma Prigogine, corroborando mais uma vez a crítica bergsoniana ao determinismo,

na física clássica podia medir-se tudo e tudo conhecer; um dos elementos, revolucionários, da física do século XX é a restrição desta visão muito simplista do universo [...] Segundo o parecer de muitos cientistas, a dinâmica clássica atingiria a sua forma definitiva e o determinismo aparecia como a própria condição da inteligibilidade. Hoje vemos que não é assim. Os novos dados constituem, sem dúvida, o cerne da revolução conceitual que atravessamos desde os primórdios do século XX. (1988, p. 47)

A leitura de algumas passagens de sua obra ${ }^{9}$ é de grande utilidade para uma aproximação entre as ideias de Bergson e a nova visão do universo decorrente da termodinâmica.

A partir de outra afirmação significativa de Prigogine (1988, p. 24), já é possível estabelecer uma relação entre as visões cosmológicas aqui discutidas, a saber: "Ler a história do universo como história de um tempo autônomo, ou de uma autonomia crescente do tempo, é, na minha opinião, uma das tentações interessantes da ciência contemporânea". O que seria esse tempo autônomo na visão de Bergson senão a própria duração? A proposta geral de Prigogine seria então conciliar a visão mecanicista à visão termodinâmica do universo. O que segundo ele se traduziria filosoficamente por uma dialética entre Einstein e Boltzmann. Ora, é claro que Bergson não pretendeu realizar este tipo de aproximação, haja vista o fato de que talvez sua intenção fosse realmente mostrar que o mecanicismo deveria ter sido na verdade substituído por uma interpretação metafísica da irreversibilidade constatada na natureza. Entretanto, uma vez que Bergson concorda em ver no mundo físico uma continuidade, ou antes, uma complementaridade com o mundo orgânico, poder-se-ia então verificar uma interseção entre sua visão e a de Prigogine. Este último dirá, através de uma afirmação, mais bergsoniana impossível, que "a vida é o reino do não-linear, a vida é o reino da autonomia do tempo, é o reino da multiplicidade das estruturas" (PRIGOGINE, 1988, p. 28).

Considerando agora a pergunta que anima a discussão cosmológica, qual seja, a de saber se o tempo teve um início, seria importante inicialmente indagar como se poderá conceber a evolução temporal no reino do determinismo que é a física clássica. Conforme Prigogine (1988, p. 36, grifos do autor), são três as exigências a se cumprir: "a irreversibilidade, o aparecimento da probabilidade e a coerência, que constituem as

\footnotetext{
9 Abordaremos as conferências "O nascimento do tempo", de 1987, e "O papel criativo do tempo", de 1984, ambas reunidas no livro $O$ nascimento do tempo. Para maiores aprofundamentos acerca das ideias de Prigogine sobre o tempo criativo, vale analisar sua obra de 1993, As leis do caos, bem como a última parte de sua obra escrita em parceria com Isabelle Stengers, A nova aliança, de 1984.
} 
condições de existência das novas estruturas que a física dos processos afastados do equilíbrio encontrou". Antes de tudo, o seu projeto prevê a necessidade de averiguar os fenômenos termodinâmicos em escala macroscópica para, em seguida, analisar até que ponto a física dos fenômenos microscópicos poderá absorver a ideia de um tempo criativo.

Como vimos, os físicos consideram a irreversibilidade negativamente, como um estado desordenado do sistema, o que se verifica exatamente na lei da entropia. Como vimos também, Bergson não atribui esse caráter negativo a tal processo, e, assim como ele, Prigogine. Para este último, a produção de entropia traduz dois elementos complementares, a saber: "um elemento criador de desordem, mas também um elemento de criação de ordem. E os dois estão sempre ligados" (PRIGOGINE, 1988, p. 39). Ou seja, se a visão clássica associa ordem a sistemas em equilíbrio e a desordem a sistemas em desequilíbrio térmico, segundo Prigogine (1988, p. 40), hoje já se vê que tal concepção é inexata. Pois, conforme suas observações experimentais, em casos de sistema em desequilíbrio (por exemplo, uma turbulência) observa-se que entre o movimento de milhões e milhões de partículas há sempre uma coerência extrema. Tratar-se-ia então de um fenômeno ordenado, ao contrário do que diriam os físicos clássicos (PRIGOGINE, 1988, p. 41).

Ainda segundo Prigogine (1988, p. 42), “[...] muitos fenômenos interessantes observados no laboratório, e que desempenham um papel fundamental no mundo que nos rodeia, não são compreensíveis a não ser baseando-nos no não-equilíbrio”. Exemplos convincentes seriam os dados da paleoclimatologia, ciência que estuda a história do clima. Conforme o físico-químico (1988, p. 42), a constatação de que seja possível atribuir uma história às mudanças climáticas da Terra "[...] implica já que a biosfera é um sistema afastado do equilíbrio". Trata-se então de um sistema irreversível, uma vez que o equilíbrio implica a anulação da flecha do tempo, pois de um sistema equilibrado não se pode dizer que tenha história.

Ao considerar-se agora a irreversibilidade, tanto em fenômenos macro quanto microscópicos, ou seja, aqueles que envolvem o estudo de átomos e moléculas, Prigogine dirá que será de fundamental relevância a noção de probabilidade. Afinal, segundo ele, ela atua tanto na descrição de sistemas dinâmicos quanto em estados quânticos. Mas como para o físico, bem como para Bergson, a irreversibilidade é comum a todo o universo, ela deve atingir também o domínio cosmológico, donde surge então, como discutimos acima, o problema de determinar a origem do todo. Não entraremos aqui no pormenor das 
especulações cosmológicas de Prigogine, apenas gostaríamos de ressaltar o fato de que, assim como Bergson, aquele autor vê na segunda lei da termodinâmica a representação do início da matéria juntamente com o tempo. Ou seja, como o próprio afirma, "foi graças ao segundo princípio que o universo se desenvolveu, e que a matéria leva em si o signo da flecha do tempo" (PRIGOGINE, 1988, p. 58).

Porém, cabe-nos aqui ressaltar uma sutileza. Foi através de indícios que concordamos haver uma defesa bergsoniana do início do tempo cósmico a partir da ação do elã vital como uma explosão originária de energia, desenvolvendo-se através das vias opostas da materialidade e da espiritualidade. Afinal, a perspectiva eternalista do cosmos é totalmente contrária ao pensamento de Bergson. Entretanto, Prigogine defenderá que o início do tempo não se deu com o big bang, mas apenas o início do nosso tempo. O que significa isto? Segundo o autor (1988, p. 59), "já no vazio flutuante o tempo preexistia em estado potencial". Ele afirma também, mais adiante, que "o tempo precede a existência, e poderá fazer nascer outros universos" (1988, p. 60). Tais palavras poderiam soar mais metafísicas que as de um metafísico bergsoniano. Não obstante o tom metafísico, o próprio Prigogine (1988, p. 59) se encarrega de esclarecer que não pretende com isto defender a eternidade do tempo, nem um eterno retorno. Porém, acredita poder pensar o tempo de modo a "transcender as categorias de devir e eternidade", coisa que novamente o reaproximaria de Bergson.

E mais um ponto será aqui digno de nota se o objetivo for aproximar as duas interpretações. Assim como o filósofo francês, Prigogine (1988, p. 60) dirá que na sua visão cosmológica “[...] é a totalidade que desempenha papel determinante". Está claro então que, ao pensar a totalidade, ambos os autores têm em vista uma concepção do todo como criação contínua, caracterizada tanto por fenômenos físicos quanto químicos, biológicos, psicológicos, sociais etc. Segundo ambos, o papel criativo do tempo é decisivo em todos os fenômenos irreversíveis do universo. Ocorre que, para Bergson, e ao que parece Prigogine tende para tal visão, todos os fenômenos seriam irreversíveis, todos seguiriam o fluxo da duração, a seta do tempo.

Mas a irreversibilidade é vista na física clássica como um grau de probabilidade, e este representaria apenas o desconhecimento das trajetórias exatas de todos os fenômenos ditos reversíveis. Hoje, dirá Prigogine (1988, p. 73-74), já não se atribui à ignorância o papel decisivo do tempo criativo. Portanto, não se poderia mais pensar o segundo princípio da termodinâmica como uma "[...] mensagem de ignorância, é uma mensagem sobre a estrutura 
do universo". O que significa dizer que processos irreversíveis não necessariamente deverão implicar destruição ou negatividade. Ora, Bergson disse o mesmo a partir de seus termos metafísicos. E completando enfim o quadro de semelhanças, vemos Prigogine (1988, p. 74) afirmar, em tom mais bergsoniano ainda, que "a evolução do universo não se deu na direção da degradação mas na do aumento da complexidade, com estruturas que aparecem progressivamente a todos os níveis, desde as estrelas e as galáxias aos sistemas biológicos".

Finalmente, a visão da temporalidade, e, em suma, da realidade física como mera repetição, ou mesmo como decadência, não parece próxima à experiência, tanto para Bergson quanto para Prigogine. Isto implicará uma compreensão mais aberta da evolução vital e material.

\section{Considerações finais: criação e evolução}

Deparando-se, enfim, com o problema de explicar a criação, Bergson (2005, p. 269) disse: "não há coisas, há apenas ações". A duração é isto, um ato livre. E assim também seria a criação, idêntica à própria duração, jorro ou fonte de novidade ininterrupta. Pensar em duração será, portanto, considerar progressos, não mais coisas ou estados. Não obstante a dualidade entre o que se faz e o que se desfaz, matéria e vida (ou espírito) seriam criações contínuas a partir de um mesmo impulso. Porém, não deverão ser pensadas como "coisas criadas", determinadas na eternidade, mas como fluxos que se criam na medida de seu próprio fazer-se.

E em qualquer parte processos criativos podem crescer, pois os mundos não devem se constituir de uma só vez, todos ao mesmo tempo, como se provaria a observação de “[...] nebulosas em processo de concentração" (BERGSON, 2005, p. 270). Enfim, todos os mundos, na cosmologia bergsoniana, jorram de um mesmo centro, todavia não se pense em um centro estático, pois não é uma coisa, é uma continuidade de jorro. ${ }^{10}$ Falar em criação,

\footnotetext{
${ }^{10}$ Bergson chegará a identificar, já na obra de 1907, este centro de onde jorra o elã vital a Deus. Assim ele diz: "Deus, assim definido, nada tem de já pronto; é vida incessante, ação, liberdade" (2005, p. 270). O desdobramento dessa noção será efetivado na obra de 1932, As duas fontes da moral e da religião. Não pretendemos aprofundar neste trabalho esse tema, porém, se lembrarmos a compatibilidade dessa visão da origem do universo com a teoria de Lemaître, que, sugestivamente, foi um padre católico, poderíamos indagar se há n'A evolução criadora a intenção de fundamentar uma cosmologia teísta, uma vez que é neste livro onde Bergson falará pela primeira vez em Deus. Segundo observou M. Capek, embora as motivações bergsonianas sejam incertas, não seria impossível que sua pretensão de fato fosse de fundo teológico, afinal este parece ser o objetivo explícito da última obra, As duas fontes da moral e da religião (Cf. CAPEK, 1971, p. 392).
} 
portanto, será reportar-se às coisas mesmas como fluxos, não como recortes praticados pela inteligência. Ver na realidade um fluxo implica, no entanto, já estar em duração, ser com ela uma só continuidade.

A dificuldade em se compreender a vida e o universo como um todo a partir desse fluxo estaria no fato de que a imobilidade assedia a consciência desde sua gênese. Deste modo, a inteligência, ao pensar a criação, supõe de antemão uma causa externa, também inteligente, a qual atribuiria ordem ao caos. Mas da perspectiva do movente, a criação é um ato contínuo e, se há causa criadora, esta deverá constituir com a duração uma só continuidade, um só movimento. O elã vital atravessa as "coisas" (matéria e espírito), é imanente a elas. ${ }^{11}$ Se a duração é um movimento, vê-se nela duas vias deste movimento, a materialidade e a vida, ou a espiritualidade.

Mas a inteligência mostra na organização da vida apenas indivíduos e espécies desconexos, fixos, ou seja, mostra partes exteriores a partes. Todavia, a unidade do elã que lhes atravessa é deixada em suspenso, pois, a inteligência parece apenas enxergar o que já está pronto, não o que se faz. Doravante, sugere o filósofo: "procuremos ver, não mais apenas com os olhos da inteligência [...] mas com o espírito, [...] essa faculdade de ver que é imanente à faculdade de agir e que jorra, de certo modo, a torção do querer sobre si mesmo" (BERGSON, 2005, p. 272). Ver-se-ia daí a evolução da vida como um processo criativo e a degradação da matéria como um progresso cíclico ${ }^{12}$ e positivo de criação de novidade. Assim sendo, se o elã vital esbarra no obstáculo material, será atribuindo-lhe o máximo de indeterminação que ele se apossará da matéria (BERGSON, 2005, p. 272).

Bergson mostrou n'A evolução criadora que tanto a vida animal quanto a vegetal constituem um esforço pela energia (seu acúmulo ou seu consumo); desta forma, uma vez que o vegetal acumula energia solar, o animal dela se aproveita através do vegetal, já que não é capaz de realizar o mesmo processo, a fotossíntese. Mas "não é para o animal que a planta acumula energia, é para o seu próprio consumo" (BERGSON, 2005, p. 276). Entretanto, o vegetal obedece a um processo lento de consumo energético, de maneira que o animal, não

\footnotetext{
${ }^{11}$ Identificando o elã vital à ação de Deus como ato criador livre, Bergson recusa a noção de transcendência do criador em relação à criação. Alguns viram nisto uma semelhança com o Deus imanente de Espinosa, mas, em cartas ao Padre Joseph de Tonquédec, em 1908 e 1912, o filósofo recusa tal associação em um sentido bastante específico. Para Bergson, não há uma mera imanência ou identidade desse Deus à natureza. Além de imanente Deus seria um princípio em atividade constante. (Cf. WORMS, 2011, p. 265).

${ }^{12}$ Ressaltamos, mais uma vez, que a ideia de um processo cíclico não implicaria, aos olhos de Bergson, um processo ad aeternum.
} 
podendo produzir ele próprio a energia necessária à sua sobrevivência e à complicação de seu sistema sensório-motor, buscará no vegetal sua fonte energética. Seria assim porque no animal o elã vital persistiu, dirigiu-se para atos livres, ao contrário do vegetal, que resignou-se a ações menos eficazes. E tal processo evolutivo teria se dado sem o concurso de qualquer influência externa, apenas pelo desdobramento das tendências opostas do elã original.

Sendo assim, haveria muito mais contingência na natureza do que necessidade. $\mathrm{Na}$ natureza apenas duas coisas são necessárias para Bergson (2005, p. 277), a saber: "1º uma acumulação gradual de energia; $2^{\circ}$ uma canalização elástica dessa energia em direções variáveis e indetermináveis, na ponta das quais estão os atos livres". O resultado dessa dupla exigência fora obtido de uma forma específica na Terra, mas poderia tê-lo sido de outra. As formas de vida que aqui se desenvolveram seriam decorrentes de determinadas "escolhas", determinadas soluções que, no fluxo da duração, se apresentaram como mais viáveis à manutenção da vida. Portanto, caso as escolhas químicas e físicas tivessem sido outras, as formas de vida que conhecemos teriam também se constituído diferentemente, “[...] teria sido outra a sua anatomia, outra a sua fisiologia” (BERGSON, 2005, p. 277). Seguir-se-á daí a afirmação da possibilidade de outras formas de vida em outros sistemas solares, "[...] formas das quais não temos ideia alguma, em condições físicas às quais ela [a vida] nos parece, do ponto de vista de nossa fisiologia, repugnar absolutamente" (BERGSON, 2005, p. 277).

Portanto, pensar em formas de vida não implicaria necessariamente pensa-las como as que estamos familiarizados, como corpos definidos ou organismos propriamente ditos. Para Bergson (2005, p. 278), enfim, “[...] a vida é possível em todo lugar em que a energia desce a encosta indicada pela lei de Carnot e onde uma causa, de direção inversa, pode retardar a descida”. Seria possível conceber, segundo o filósofo, a conservação da energia para doravante ser gasta em uma matéria ainda não solidificada. Algo que poderia muito bem ter ocorrido com as condições iniciais de vida na nebulosa da qual surgira nosso planeta, antes de completada a condensação da matéria. ${ }^{13}$

Assim, o impulso vital, embora permanecendo o mesmo, poderia ter originado outras formas de vida caso as condições físicas e químicas do nosso mundo fossem outras. Mas daí não seria possível determinar sob quais tendências sua cisão se efetivaria. Além disso, não

\footnotetext{
${ }^{13}$ Segundo a teoria nebular de P. S. de Laplace, o sistema solar teria se originado de uma nebulosa, ou seja, uma nuvem de gás e poeira há aproximadamente cinco bilhões de anos. A hipótese nebular fora apresentada por Laplace em sua obra Exposition du systeme du monde, em 1796, influenciado pelas ideias de Kant acerca da origem do sistema solar, bem como pela mecânica de Newton. (GLEISER, 2013, p. 192-204).
} 
seria possível mesmo determinar sua cisão (BERGSON, 2005, p. 278). A imagem do elã vital, no entanto, é apenas uma imagem que, segundo Bergson, estaria mais próxima à fluidez da realidade, uma maneira talvez menos estática de se pensar a evolução. Mas as categorias da unidade e da multiplicidade, sendo quadros da inteligência, não seriam suficientes para exprimir a realidade desse fluxo em seu fazer-se, tanto no que concerne à vida interior quanto à vida em geral, mas também no que concerne à matéria.

Finalmente, se é possível afirmar algo explícito no pensamento evolutivo-cosmológico de Bergson, por mínima que seja sua abordagem acerca deste tema, é a ideia de indeterminação do porvir. E, neste sentido, nem o mecanicismo físico, nem quaisquer concepções teológicas poderão determiná-lo definitivamente. Afinal, lembrando as advertências levantadas n'A evolução criadora, no contexto desta filosofia, o sucesso da evolução, atingindo até então seu ápice na espécie humana, não garante a esta um futuro glorioso. Pois, embora a segunda lei da termodinâmica tenha sido interpretada por Bergson concebendo a degradação da energia positivamente como um processo criativo, a extinção da espécie humana, bem como de toda a vida orgânica na Terra, não deixa de ser uma virtualidade implícita ao fluxo do elã. Não necessariamente, entretanto, pela mínima probabilidade de um retorno, apontado por Boltzmann, ao estado de equilíbrio termodinâmico universal, mas pelo próprio comportamento humano diante da natureza. Pois, por não perceber sua aderência ao elã da vida, o homem tornou-se a si mesmo sua principal ameaça.

A nova metafísica não estaria completa se não indagasse a questão cosmológica sobre a origem do universo em seu conjunto. Não bastou a Bergson indagar sobre o princípio da vida orgânica n'A evolução criadora, foi imprescindível investigar também o princípio da materialidade. E, como vimos, não se tratam de princípios absolutamente distintos. Sendo assim, sua cosmologia será doravante entendida como corolário de sua metafísica, afinal dessas reflexões uma filosofia da natureza tal qual a bergsoniana não poderia se privar.

\section{REFERÊNCIAS BIBLIOGRÁFICAS}

BERGSON, H. Ensaio sobre os dados imediatos da consciência. Lisboa: Edições 70, [S. d.]. . A evolução criadora. São Paulo: Martins Fontes, 2005. As duas fontes da moral e da religião. Coimbra: Almedina, 2005a. 
CAPEK, M. Bergson and modern physics. Dordrecht/Boston: D. Reidel Publishing Company, 1971 (Boston studies in the Philosophy of science, VolumeVII).

GLEISER, M. A dança do universo. São Paulo: Companhia de Bolso, 2013.

KOYRÉ, A. Do mundo fechado ao universo infinito. Rio de Janeiro: Forense Universitária, 2006.

MONTEIRO, G. A medida do tempo: intuição e inteligência em Bergson. Salvador: Quarteto Editora, 2012.

PINHO, S. T. e ANDRADE, R. F. S. Evolução das ideias da termodinâmica e da mecânica estatística. In: ROCHA, J. F. (org.). Origens e evolução das ideias da fisica. Salvador: EDUFBA, 2002.

PRIGOGINE, I. O nascimento do tempo. Lisboa: Edições 70, 1988.

PRIGOGINE, I. As leis do caos. São Paulo: Editora UNESP, 2002.

PRIGOGINE, I e STENGERS, I. A nova aliança. Brasília: Editora UnB, 1997.

VERNANT. J.P. O universo, os deuses, os homens. São Paulo: Companhia das letras, 2015.

WORMS, F. Bergson ou os dois sentidos da vida. São Paulo: Ed. UNIFESP, 2011. 